\title{
BM] Global Health WHO essential medicines for reproductive health
}

\author{
Roopan Gill (D), Bela Ganatra, Fernando Althabe
}

To cite: Gill R, Ganatra B, Althabe F. WHO essential medicines for reproductive health. BMJ Global Health 2019;4:e002150. doi:10.1136/ bmjgh-2019-002150

Handling editor Seye Abimbola

Received 8 November 2019 Accepted 17 November 2019

Check for updates

(c) Author(s) (or their employer(s)) 2019. Re-use permitted under CC BY-NC. No commercial re-use. See rights and permissions. Published by BMJ

Department of Sexual \& Reproductive Health and Research, World Health Organization, Geneva, Switzerland

Correspondence to

Dr Roopan Gill;

roopan.gill@gmail.com
Since 1977, the WHO's Model List of Essential Medicines has been a rigorous evidence-based document providing a list of essential and lifesaving medicines. Specifically, over the course of the last few decades, a large body of scientific evidence and programmatic use has accumulated for existing medicines for reproductive health and the development of new life-saving therapies. The 21st edition of the WHO Model List of Essential Medicines issued in June 2019, added heat stable carbetocin and tranexamic acid (TXA) to the core list of medicines for reproductive health and moved mifepristone and misoprostol from the complementary to the core list. All of these medicines are important for preventing the leading causes of maternal morbidity and mortality. ${ }^{1}$

Uterotonics and TXA are pivotal for management of postpartum haemorrhage (PPH), which continues to be the leading cause of maternal deaths in most low-income countries. ${ }^{2}$ Decades of evidence have demonstrated that PPH can be prevented by the prophylactic administration of uterotonics during the third stage of labour. Typically, in settings where multiple uterotonic options are available, oxytocin (10 IU, intramuscular/intravenous (IM/IV)) is the recommended agent for the prevention of PPH for all births. ${ }^{3}$ However, oxytocin is sensitive to heat exposure and must be transported and stored at $2-8^{\circ} \mathrm{C}$ continuously. ${ }^{4}$ This represents a problem in low-resource settings where the cold chain is difficult to maintain. Following the availability of new evidence, the 2018 updated WHO recommendations on the use of uterotonics for PPH prevention recommends carbetocin in settings where oxytocin is not available or its quality cannot be guaranteed, and its cost is comparable to other effective uterotonics. ${ }^{3}$ Heat stable carbetocin does not require refrigeration and therefore eliminates the barriers associated with refrigerated storage and transport for non-heat-stable uterotonics, making this a viable and important option for prevention of $\mathrm{PPH}$.
In addition to this, WHO recommends the use of TXA as part of the standard treatment package. ${ }^{5}$ Based on the results of a large randomised controlled trial early use of TXA reduced death due to bleeding in women with $\mathrm{PPH}$, regardless of the cause, and with no adverse maternal effects. ${ }^{6}$ TXA is relatively cheap, easy to administer and it is often available in healthcare settings due to its use in trauma and surgery. This agent was already included in the Essential Medicine List (EML) since 2011, but for the treatment of patients with trauma. The 2019 EML now includes TXA also as a core medicine for reproductive health to treat PPH.

Unsafe abortion is the fourth leading cause of maternal mortality globally. Nearly 25 million unsafe abortions occur worldwide each year and most of these $(97 \%)$ take place in low-income and middle-income countries. The combination of mifepristone followed by misoprostol used for the medical management of abortion were added to the complementary list of essential medicines in 2005 as important reproductive health medications to decrease maternal mortality and morbidity due to unsafe abortions. Since 2005, evidence has accumulated documenting the safety and effectiveness of these medications in clinical trials and programmatic use. WHO guidelines recommend that they can be provided at primary care level and by non-physician providers. Specialised investigations are not needed and the process can be managed outside of a facility and without the direct supervision of the provider. ${ }^{8-15}$ Service delivery with limited medical supervision can improve privacy, convenience and acceptability of the abortion process without compromising safety and effectiveness. Moving these medications to the core list and removal of the stipulation that direct supervision is required is aligned with the evidence and guidance generated through the last decade.

All three medications have been added to the core list, which means that these medications 
do not require specialised diagnostic or monitoring facilities and/or specialist care and/or training. These changes to the core list of the 21st WHO Model List of Essential Medicines provide an opportunity for ministries of health, non-governmental organisations, national and international associations and civil society organisations to advocate for their inclusion to national essential medicine lists. Aligning with the global commitments to strengthening primary healthcare and access to universal health coverage, access to these essential Sexual and Reproductive Health (SRH) medicines will contribute to these commitments to ensure that access to life-saving medicines are available for all women globally, leaving no one behind.

Contributors $R G$ conceptualized and wrote the initial draft. BG and FA provided comments and edits.

Funding This work was supported by the UNDP-UNFPA-UNICEF-WHO-World Bank Special Programme of Research, Development and Research Training in Human Reproduction (HRP), a cosponsored program executed by the World Health Organization (WHO).

Competing interests None declared.

Patient consent for publication Not required.

Provenance and peer review Not commissioned; externally peer reviewed.

Data availability statement № additional data are available.

Open access This is an open access article distributed in accordance with the Creative Commons Attribution Non Commercial (CC BY-NC 4.0) license, which permits others to distribute, remix, adapt, build upon this work non-commercially, and license their derivative works on different terms, provided the original work is properly cited, appropriate credit is given, any changes made indicated, and the use is non-commercial. See: http://creativecommons.org/licenses/by-nc/4.0/.

ORCID iD

Roopan Gill http://orcid.org/0000-0001-6984-5800

\section{REFERENCES}

1 WHO. 22nd Expert Committee on the Selection and Use of Essential Medicines - Application for Mifepristone-Misoprostol, 2018.

2 Say L, Chou D, Gemmill A, et al. Global causes of maternal death: a who systematic analysis. Lancet Glob Health 2014;2): :e323-33.10.1016/S2214-109X(14)70227-X

3 WHO. WHO Recommendations: Uterotonics for the prevention of postpartum haemorrhage. World Health Organization, 2018.

4 WHO/PQT, Oxytocin injection. Clarification of stability data and storage statement requirements. 31. Guidance document, 2018.

5 WHO. WHO recommendation on tranexamic acid for the treatment of postpartum haemorrhage. World Health Organization, 2017.

6 Shakur H, Roberts I, Fawole B, et al. Effect of early tranexamic acid administration on mortality, hysterectomy, and other morbidities in women with post-partum haemorrhage (woman): an international, randomised, double-blind, placebo-controlled trial. The Lancet 2017;389:2105-16

7 Ganatra B, Gerdts C, Rossier C, et al. Global, regional, and subregional classification of abortions by safety, 2010-14: estimates from a Bayesian hierarchical model. The Lancet 2017;390:2372-81.

8 Sjöström S, Dragoman M, Fønhus MS, et al. Effectiveness, safety, and acceptability of first-trimester medical termination of pregnancy performed by non-doctor providers: a systematic review. BJOG: Int J Obstet Gy 2017;124:1928-40.

9 Raymond EG, Shannon C, Weaver MA, et al. First-Trimester medical abortion with mifepristone $200 \mathrm{Mg}$ and misoprostol: a systematic review. Contraception 2013;87:26-37.

10 Raymond EG, Blanchard K, Blumenthal PD, et al. Sixteen years of Overregulation: time to Unburden Mifeprex. N Engl J Med 2017:376:790-4.

11 Barnard S, Kim C, Park MH, et al. Doctors or mid-level providers for abortion. Cochrane Database Syst Rev 2015;76.

12 Winikoff B, Dzuba IG, Chong E, et al. Extending outpatient medical abortion services through 70 days of gestational age. Obstet Gynecol 2012:120:1070-6.

13 WHO. Safe Abortion: Technical and Policy guidance for Health Systems. 2nd edn. Geneva: World Health Organization, 2012.

14 WHO. Health worker roles in providing safe abortion care and postabortion contraception. Geneva: World Health Organization, 2015.

15 WHO. Who recommendations for medical management of abortion. Geneva: World Health Organization, Forthcoming, 2018. 